\title{
La Convención sobre los derechos del niño de las Naciones Unidas y la reforma del derecho de custodia y de visita en Alemania*
}

\author{
Christoph ஜ̈enicke
}

Professor Assistente da Universidade de Heidelberg no Instituto de Direito Estrangeiro e Direito Internacional; Doutor em Direito pela Universidade de Heidelberg

\section{Introdución}

24

lemania se encuentra en una nueva

etapa de reformas del derecho de familia. En los últimos años el gobierno presentó proyectos de reforma para diferentes temas del derecho de familia.

\begin{abstract}
Este es la versión escrita y ampliada de una conferencia dada el 9 de abril de 1997 en la Universidad Federal de Rio Grande de Sul.

Literatura citada en forma abreviata: Baer (1993), Übereinkommen der Vereinten Nationen ueber die Rechte der Kinder, NJW 993, 2209; Baer (1989), Neue Lösungen im Kindschaftsrecht, ZRP 1989, p. 344; Beitzke/Luederitz, Familienrecht, 26. ed. Muenchen 1992; Broetel (1996), Die Defizite im deutschen Kindschaftsrecht, gemessen an der Europaeischen Menschenrechtskonvention (EMRK), en Koeppel (ed.), Kindschaftsrecht und Voelkerrecht, Neuwied 1996, p. 49; Broetel (1996a), Der Rechtsanspruch des Kindes auf seine Eltern, DAVorm 1996, p. 745; Buettner,Kindschaftsrechtsreform in England, FamRZ 1996, 464; Coester (1995), Elternrecht des nichtehelichen Vaters und Adoption, FamRZ 1995, p. 1245; Coester (1996), Elternautonomie und Staatsverantwortung bei der Pflege und Erziehung von Kindern, FamRZ 1996, p. 1181; Dopffel (ed), Kindschaftsrecht im Wandel, Tübingen 1994: Dorsch, Die Konvention der Vereinten Nationen über die Rechte der Kinder, Berlin 1994; Ebert, Die Defizite im deutschen Kindschaftsrecht gemessen an der UN-Kinderrechtskonvention, en Koeppel (ed.). Kindschaftsrecht und Voelkerrecht, Neuwied 1996, p. 103. Gernhber/Coester-Waltien. Familienrecht 4. od. Muenchen 1994: Henrich (1994). Entwicklungslinien eur ous Kind Konch Kont Merk, Laencives Motivos del proyecto de ley. Entwurt eines Gesetzes zur Reform des Kindschalsrechts (Kindschantsreformgeselz - KindRG) mit Begrandung, en. Drucksache des Deulschen Bundestages 13/4099; Nave-Herz, Kinder mil nich-sorgeberechliglen Vatern, FuR 1995, p. 102; Schwab/Wagenitz, Einführung in das neue Kindschaftsrecht, FamRZ 1997, p. 1377, de Zayas, Das deutsche Kindschaftsrecht und der UN-Zivilpakt (IPBPR) von 1966, en Koeppel (ed.), Kindschaftsrecht und Voelkerrecht, Neuwied 1996, p. 91; Zimmermann, Neuere Entwicklungen zum Verhältnis zwischen dem UN-Abkommen über die Rechte des Kindes und nationalem Familienrecht, IPRax 1996, p. 167.
\end{abstract}


Este año, dos leyes de reforma fueron votadas. El "Gesetz zur Reform des $\mathrm{K}$ i n d s c hafts e c ht s " 1 (Kindschaftsrechtsreformgesetz; ley de reforma del derecho del niño) y el "Gesetz zur Abschaffung der Amtspflegschaft und zur Neuordnung des Rechts der Beistandschaft"2 (Beistandschaftsgesetz; ley de asistencia). Dos proyectos de reformas se encuentran todavía en el próceso legislativo. El "Erbrechtsgleichstellungsgesetz" (ley para la realisación de la igualdad de los hijos extramatrimoniales en el derecho sucesorio) y el "Kindesunterhaltsgesetz" (ley sobre el derecho alimenticio de hijos).

Un tema que atrayó atención especial, es la reforma del derecho de custodia y de visita de los niños que se realizó finalmente por el Kindschaftsrechtsreformgesetz que entrerá en vigor el 1 de julio de 1998. Se trata a un lado, de la cuestión si los padres, que no están casados, pueden obtener la custodia en común. Al otro lado se plantean cuestiones de custodia y de visita cuando los padres se separan o se divorcian.

Las reglas de la Constitución y de convenios internacionales en la materia tuvieron y tienen una gran influencia en la discusión sobre la reforma. Ellas sirvien como puntos de referencia para posibles y necesarias nuevas reglas del derecho de familia. La Convención sobre los derechos del niño de las Naciones Unidas es uno de estos convenios que contiene estipulaciones especificas sobre el derecho del niño en cuanto a la custodia de sus padres. La otra convención internacional que tiene una gran influencia en la discusión sobre la reforma del derecho de familia en Alemania, es la Convención de los los derechos humanos del Consejo de Europa.

En este ensayo quiero presentar la Convención sobre los derechos del niño de las Naciones Unidas en general y las reglas concernientes el derecho de custodia y de visita en especial. Después voy a mostrar el derecho alemán en esta materia, la ley actual y la reforma y analisar, si está en acuerdo con las exigencias de la Convención sobre los derechos del niño.

\section{La Convención sobre los derechos del niño}

\section{Generalidades}

La Convención sobre los derechos del niño fue aprobada el 20 de noviembre de 1989, treinta anos después de la decla-

Abbrevaciones: AG: Amtsgericht (tribunal de primer instancia); BGB: Bürgerliches Gesetzbuch (código civil alemán); BVerfG: Bundesverfassungsgericht (Corte Constitucional de la RFA); BVerGE: Amtliche Sammlung der Entscheidungen des Bundesvertassungsgerichts (coleción oficial de las deciciones); Bundesverassungserich (Corlecilon FamRZ : Zeltschit tue Verfahrensrechts;

1. Proyecto del gobierno con motivos en: Bundestag Drucksachen 13/8511; los materiales públicados del processo legislativo pueden ser consultado por el Internet (http://www.bundestag.de/datbk/datbk.htm); estas leyes cambian las reglas pertinentes en los existentes códigos, especialmente en el código civil.

2. Proyecto del gobierno con motivos en: Bundestag Drucksachen $13 / 8509$.

3. Proyecto del gobierno con motivos en: Bundestag Drucksachen $13 / 8510$.

4. Proyecto del gobierno con motivos en: Bundestag Drucksachen $13 / 7338$.

Revista da Faculdade de Direito da UFRGS, v. 13, 1997

ración de los derechos del niño de la Asamblea General de las Naciones Unidas. Esta declaración es la base de la convención ${ }^{5}$. Como declaración no tiene un carácter obligatorio. Se entiende como una llamada a los padres, a los hombres individuales, a las organisaciones voluntarias, a las autoridades locales como a los gobiernos nacionales de reconocer los derechos del niño y trabajar para su observancia ${ }^{6}$. La convención es un tratado del derecho internacional público que tiene un carácter obligatorio por el estado que lo adopta. Además, la convención está muy ligado con el art. 24 del International Convenant on Civil and Political Rights of $1966^{7}$ y está considerada como un convenio especial de la materia del art. $24^{8}$.

La elaboración de la convención tardó diez años y se hizo en negociaciones laboriosas en un grupo de trabajo del Consejo Económico y Social de las Naciones Unidas. Una vez elaborada, la convención conoció un éxito estupendo. Hasta el 30 de setiembre de 1990, 50 estados ya lo habían

ratificado. Y hasta hoy más de 180 , es decir casí la totalidad de los Estados del mundo, 1 ahan adoptado. Alemania ratificó la convención relativamente tarde el 5 de abril de $1992^{10}$.

El éxito sobresaliente en cuanto a las ratificaciones es muy importante y laudable. Al mismo tiempo este éxito sorprende, tomando en cuenta las arduas discusiones al redactar la convención. Así pueden surgir ciertas dudas en cuanto a la efectividad de sus obligaciones. Muchos estados formularon reservas a la convención en el momento que la ratificaron. El Iran la ratificó con la reserva de que no está obligado por ella, por cuanto que existe oposición con el derecho islámico ${ }^{11}$. También Alemania formuló reservas ${ }^{12}$. A un lado excluyó la aplicación en el plan interno. Por consecuencia una persona individual no puede invocar una de sus dispociciones directamente contra el estado ${ }^{13}$. Alemania declaró entre otros que el art. 18 par. 1 no afectaría las existentes reglas en cuanto al derecho de custodia y de visita de los padres ${ }^{14}$. Además, no que-

5. Broetel (1996a) p. 843.

6. Declaration of the Rights of the Child (1386 [XIV] Preamble: ".. and calls upon parents, upon men and women as individuals, and upon voluntary organisations, local authorities and national Governments to recognize these rights an strive for their observanve ..." citado según Dorsch, p. 331.

7. Ratificado por Alemania por la ley del 15.11.1973, BGBI. II (1973) p. 1533.

8. Ebert, p. 105

9. Dorsch, 70 ss.

10. Zustimmungsgesetz del 17.2.1992, BGBI. 1992 II, p. 121.

11. El 13.7.1994; varios Estados formularon oposiciones contra esta reserva, ver StAZ 1996, p. $220 \mathrm{~s}$.

12. Ver la discusión sobre la compatibilidad de las reservas con art. 52 par. 1 Dorsch, 310; Baer, 2210; Wolf, Ratifizierung unter Vorbehalt: Einstieg oder Ausstieg der Bundesrepublik Deutschland aus der UN-Konvention über die Rechte des Kindes?, ZRP 1991, 374, 378; Broetel (1996a) p. 852

13. Meng, p. 6, 15: En el derecho internacional público no existe una obligación general que un convenio internacional tiene que ser aplicable directamente en el plan interno; existe un margen de discrecionalidad para el estado por que mecanismo cumplirá las obligaciones aceptadas.

14. Text der Erklärung der Bundesregierung aus Anla $B$ der Hinterlegung der Ratifikationsurkunde citado en Dorsch, 399; a pesar de esta reserva unos tribunales de primer instancia aplicaraon el ar. 18 directamente, AG Bremen, FamRZ 1995, 317; AG Kamen, FamRZ 1995, 1077, ver la crítica por Meng, p. 28.

Revista da Faculdade de Direito da UFRGS, v. 13, 1997 
da siempre claro a qué grado las dispociones de la convención tienen un carácter obligatorio o sólo de "soft law" es decir carácter de una llamada ${ }^{15}$.

A pesar de estas dudas, en cuanto al carácter obligatorio de las diferentes dispociones, la convención es un progreso de suma importancia para el reconocimiento y la observación de los intereses y derechos del niño. Es la primera vez, que casí la totalidad de los estados reconocen por medio de una convención los principales derechos del niño. Estableció una agenda para hacer las leyes de los diferentes estados conformes con los derechos fundamentales del niño. Tiene como efecto que el tema de los derechos de los menores sea discutido constantamente en el plan internacional ${ }^{16}$. La convención creó un comité que está a cargo de supervizar el cumplimiento de las obligaciones aceptadas por los estados participantes, art. 43 par. 1. Los estados se obligaron a presentar con regularidad un informe al comité, que tiene que publicarse también en el mismo país (art. 44). La competencia de este comité no equivale a un control judicial como previsto por la Convención de los los derechos humanos del Consejo de Europa. Pero este mecanismo de supervisión puede ser eficaz, utilizando la influencia de la opinión pública.

Bien que las disposiciones de la convención no contienen muchas veces obli-

15. Broetel (1996a) p. 845; Meng, p. 23.

16. Meng, p. 24.

17. BVerfG 26.3.1987, BVerfGE $74,358,370$.

18. Meng, p. 16.

19. Meng, p. 10

20. Es de mayor importancia en esta discusión el art. 8 de la Convención de los los derechos humanos del Consejo de Europa que garantiza la vida familiar. La corte de Estrasburgo ha dado a este articulo una importancia especial sobre todo para la protección gaciones muy definidas. Ellas tienen una gran influencia en el plan interno. A un lado son de importancia en la discusión politica cuando existe un proyecto de reforma de la materia, como es el caso en Alemania en este momento. Además, tienen una influencia en la interpreteación de las dispociones de las garantías de los derechos fundamentales, que se encuentran en la constitución. La Corte Constitucional alemana reconoce expresamente que la interpretacion de las garantías individuales de la constitución tiene que tomar en cuenta el contenido y el desarrollo de las garantías individuales de la Convención de los los derechos humanos del Consejo de Europa ${ }^{17}$. Esta influencia en la interpretación tiene que valer también para otros convenios de garantías individuales, como la Convención sobre los los derechos del niño puede hacer más claro para el art. 6 de la constitución alemana que contiene la garantía del matrimonio y de la familia y su protección por el Estado que los derechos de los padres en cuanto a los niños tienen un caracter fiduciario y están atribuidos sobre todo en el interés de los niños ${ }^{19}$. En Alemania la doctrina está discutiendo la reforma del gobierno con mucha atención a las reglas de convenciones internacionales ${ }^{20}$. De importancia son sobre todo la Convención de los los derechos humanos del Consejo de Europa y la derechos del niño ${ }^{18}$. La Convención sobre
Convención sobre los derechos del niño de las Naciones Unidas ${ }^{21}$.

\section{Las reglas pertinentes al} derecho de custodia y de visita

Antes de discutir la reforma del derecho de familia en Alemania quiero presentar las reglas de esta convención pertinentes al derecho de custodia y de visita.

\section{a) Art. 3}

El art. 3 par. 1 dice: En todas las medidas concernientes a los niños que toman las instituciones (públicas o privadas) de bienestar social, las autoridades administrativas o los órganos legislativos, una consideración primordial a que se atenderá será el interés superior del niño.

Hay que prestar atención a que el interés del niño no sea mencionado como la única consideración primordial. La convención se refiere al interés superior del niño solamente como una de las consideraciones principales, entre otras. A pesar de esto, la importancia del art. 3 par. 1 consiste en que declara el interés superior del niño, como la idea dominante para la interpretación y la aplicación de la convención. $\mathrm{El}$ énfasis, que la convención da al interés del niño, hace claro que el niño no sea objeto de los intereses y derechos de los padres.

\section{b) Art. 7}

En el art. 7 par. 1 se establece que el niño tiene, desde que nace, el derecho de conocer a sus padres y a ser cuidado por ellos, en la mejor medida posible. Este artículo contiene la primacía de la educación por los propios padres. Se refiere a instituciones, como la adopción, a los cuales hay que atribuir un carácter subsidiario ${ }^{22}$. Es importante remarcar que la prioridad de la crianza por los propios padres no está formulada como un derecho de los padres. $\mathrm{Al}$ contrario es concebido como un derecho propio del niño.

\section{c) Art. 9 par. 3}

El art. 9 par. 3 obliga a los estados a respetar el derecho del niño, que está separado de uno o de ambos padres, a mantener relaciones personales y contacto directo con ambos padres de modo regular, salvo si ello es contrario al interés superior del niño.

Al principio de los trabajos preparatorios este reglamento fue proyectado para promover el reagrupamiento de la familia, cuando ésta estuviera separada por linderos nacionales. En el proceso de la redacción, el fin de la regla se cambió. Ahora el reglamento visa para asegurar en forma general la relación entre padres e hijos. Mientras el ámbito de aplicacón fue extendido, la aplicación directa fue excluida. La formulación final que se adoptó establece so-

de las relaciones personales entre el hijo extramatrimonial y su padre, ver Broetel (1996) p. $51 \mathrm{~s}$; otro convenio pertinente es el International Convenant on Civil and Political Rights of 1966, que contiene en art. 23 y 24 reglas sobre los derechos del niño y de la familia, ver de Zayas, p. 91 ss.

21. Bien que los motivos del proyecto del gobierno mencionan solo una vez la Convención sobre los derechos del niño y en absoluto la Convención de los los derechos humanos del Consejo de Europa.

22. Ver también el art. 21 de la Convención; Lima Marques, Das Subsidiaritātsprinzip in der Neuordnung des internationalen Adoptionsrechts, Frankfurt/Main 1997, p. 80 ss. 
lamente una obligación de los estados y no atribuye a los interesados, derechos subjetivos que puedan ser invocados directamen$\mathrm{te}^{23}$.

d) Art. 18 par. 1

El art. 18 par. 1 constata que los estados de su parte pondrán el máximo empeño en garantizar el reconocimiento del principio, de que ambos padres tienen obligaciones comunes, en lo que respecta a la crianza y el desarrollo del niño. Incumbirá a los dos padres o, en su caso, a los representantes legales la responsabilidad primordial de la crianza y el desarrollo del niño. Su preocupación fundamental será el interés superior del niño.

Este artículo utiliza la noción "empeño". Esto significa que contiene solamente una obligación de los estados. Ellos tienen que esforzarse para cumplir las obligaciones. No confiere a los individuos derechos directamente actuables. El artículo es el reglamento específico en cuanto a los derechos y obligaciones de los padres a criar sus propios hijos. La convención no habla de un derecho de los padres de criar a los hijos. Más bien utiliza locuciones como "tienen obligaciones" e "incumbirá a los padres". De esta manera pone de nuevo el énfasis en el derecho de los niños.

En un primer plano, este árticulo contiene la primacía de que un niño sea criado y educado por sus propios padres. Esta primacía limíta todas intervenciones

estatales y los pone bajo la obligación de ser justificadas, especialmente por razones del bienestar del niño. Al hablar de las obligaciones comunes de ambos padres, este árticulo visa en un segundo plano a promover la igualdad del padre y de la madre en cuanto a la educación de sus hijos. Así el art. 18 par. 1 se rebela contra una discriminación de la madre, existente sobre todo en países islámicos. Este árticulo contiene todavía otro aspecto. No utiliza la locución de que ambos padres tienen obligaciones iguales, pero se sirve de la noción de las obligaciones comunes. Esto significa que no tiene como fin únicamente el ejercicio de igual manera de las obligaciones paternales, cuando los dos padres están encargados de la crianza.

Además, contiene la obligación de los estados de garantizar, lo máximo posible, que ambos padres están encargados comunes de la educación de sus hijos. Este último elemento del art. 18 par. 1 fue la causa por la cual Alemania formuló la citada reserva contra este árticulo, al ratificar la convención. Como voy a demostrar en lo siguiente, el derecho alemán actual no satisface a esta exigencia del art. 18 par. 1 . En consecuencia, la interpretación del art. 18 par. 1 está muy discutida en Alemania ${ }^{24}$. Pero por un lado, el tenor literal es muy claro. Otros convenios internacionales que visan a asegurar la igualdad de los sexos con respecto a los derechos u obligaciones, usan siempre la noción derechos u obligaciones iguales y no comunes ${ }^{25}$. Además, el art. 18 está centralizado hacía los derechos del

23. Broetel (1996a) p. 848.

24. Para una interpretación más limitada ver Stoecker, Die UNO-Kinderkonvention und das deutsche Familienrecht, FamRZ 1992, p. 245,250 .

25. Zimmermann, p. 169. niño. El menor tiene el interés primordial de que los dos padres se ocupen de su educación. Desde el punto de vista del niño, la igualdad al ejercer estas obligaciones es secundaria ${ }^{26}$.

\section{e) Conclusiones}

Resumiendo se puede constatar: La convención tiene un éxito sobresaliente en cuanto al número de ratificaciones. Está centralizada en el niño. El estatuto del niño no está concebido como el objeto de los derechos de los padres. Al contrario, es el niño el que tiene derechos propios, a los cuales corresponden obligaciones de los padres, así como de los estados. La convención no establece siempre derechos individuales, que puedan ser invocados directamente contra un estado. Pero contiene obligaciones de los estados, de garantizar y promover la realización de los derechos. De esta manera, la convención crea un ordenamiento de valores funda mentales. La idea dominante para la interpretación y la aplicación de la convención es el interés superior del niño. Los ordenamientos jurídicos internos de los Es. tados tienen que ser medidos con estos valores fundamentales.

\section{El derecho alemán interno, en cuanto a la custodia y a la visita de menores - situación acutal y la reforma}

Después de haber dado un esquema de la Convención sobre los derechos del

26. Zimmermann, p. 169

27. Meng, p. 9; Ebert, p. $108 \mathrm{~s}$ niño, quiero presentar el derecho alemán en cuanto a la custodia y la visita de menores. Voy a tratar la situación actual y la reforma. La exposición va a ser acompañada de la investigación para comprobar, si las reglas satisfacen a las exigencias de la Convención sobre los derechos del niño. Antes de entrar en el estudio de las reglas particulares, quiero presentar un resumen de la situación general del derecho de familia en Alemania.

\section{Situación general del derecho}

de familia en Alemania

El derecho de familia actual en Alemania se caracteriza por la necesidad de reformas legislativas que está generalmente aceptada ${ }^{27}$. La ultíma gran reforma del derecho de familia data de los años 1979/ 1980. Las reglas vigentes, no corresponden en muchos aspectos a la evolución sociológica de la sociedad. Varias normas fueron declaradas inconstitucionales por la Corte Constitucional Federal. En cuanto a otras reglas, la Corte Constitucional se abstuvo de declararlas nulas, pero reclamó la necesidad de reformas legislativas.

Por otro lado, existe en el derecho de familia una desunión entre el territorio de la antigua República Demócrata Alemana y el territorio de la antigua República Federal Alemana. En la República Demócrata Alemana la distinción entre hijos extramatrimoniales había sido abolida en el ano 1965. Con la unificación de las dos Alemanias casi la totalidad de las reglas de derecho de la República Federal fueron in- 
troducidas en el territorio de la República Demócrata Alemana. De esta manera el tratamiento distinto de los hijos extramatrimoniales fue reintroducido en esta parte. Sólo en unos aspectos, como en cuanto al derecho sucesorio la igualdad fue mantenida, pero solamente para el territorio de la Ex-República Demócrata Alemana. En el tratado, que realizó la unificación, fue incluido la constatación de que una reforma del derecho de los hijos extramatrimoniales tiene que hacerse de la manera más rápida posible.

Otra razón, para realizar las reformas consiste en la declaración del gobierno alemán, al ratificar la Convención de los derechos del niño. Cuando el gobierno federal formuló las mencionadas reservas, declaró la voluntad de aprovechar la ocasión de ratificar la convención para introducir reformas del derecho interno, que corresponden al espíritu de la convención. Esta declaración menciona expresamente una reforma del derecho de custodia de los hijos, cuyos padres nunca han estado casados o están separados o divorciados.

\section{La distinción entre hijos matrimoniales y extramatrimoniales}

El régimen normativo actual del derecho de custodia y de visita en Alemania, está caracterizado por la distinción entre los hijos matrimoniales y extramatrimoniales. Esta distinción está basada en un concepto de la paternidad extramatrimonial, que aho-

ra no corresponde y talvez nunca ha corespondido a la realidad social. Según el código civil en la redacción original, el padre y el hijo extramatrimonial no eran parientes en el sentido legal. Sólo existía una obligación alimenticia, pero ningunos derechos u obligaciones de educación o crianza. El hijo estaba adscrito unicamente a la madre. Pero el derecho de custodia de ésta estaba muy limitado por la tutela oficial, que existía para cada hijo extramatrimonial. Estas reglas estaban vigentes hasta el año $1970^{28}$.

El concepto ideológico de este reglamento era la idea que los hijos ilegítimos provenían de relaciones pasajeras entre hombres casados o jóvenes de buena familia con mujeres o muchachas moralmente de mala reputación. El derecho visaba protejer la familia del hombre de todo lo inconviente del escándalo de un hijo extramatrimonial ${ }^{29}$. La tutela oficial tenía el fin, de vigilar sobre la madre que fue juzgada como moralmente dudosa.

Me parece que hasta en aquellos tiempos, la conformidad de este concepto con la realidad era dudosa. Antes de la primera guerra mundial, la tasa de hijos extramatrimoniales era en Alemania de $10 \%$ y siempre existían muchas otras constelaciones por nacimientos ilegítimos. Un ejemplo es que después de la segunda guerra mundial, las viudas de soldados muertos en la guerra no contrayeron matrimonio con la nueva pareja para no perder su derecho de pensión ${ }^{30}$. El reglamento de la ley parecía corresponder en aquellos tiempos

28. Henrich (1995) p. $244 \mathrm{~s}$

29. Así la descripción critica de Rupp-von Brünneck, Zur Einführung in das neue Recht der nichtehelichen Kinder, StAZ 1970, p. 226. 30. Broetel (1996a) p. 748.

Revista da Faculdade de Direito da UFRGS, v. 13, 1997 menos a la realidad sociológica, sino a la manera en que los redactores del código y su clase social percibieron la problemática.

La reforma, que se hizo en el año $1970^{31}$, era muy atrasada. La constitución de la República Federal del año 1949 contiene en el art. 6 par. 5 el mandato al legislador de crear para los hijos extramatrimoniales condiciones iguales a las de los hijos matrimoniales en cuanto a su desarrollo físico y psíquico y además en cuanto a su posición en la sociedad. El cumplimiento de este mandato ha tenido que ser reclamado repetidas veces por la Corte Constitucional $^{32}$. La nueva ley mejoró substantivamente la posición legal del hijo extramatrimonial y la acercó casi totalmente a la de un hijo legal. Aunque fueron mantenidos ciertas diferencias. Estas se encuentran a un lado en el derecho sucesorio ${ }^{33}$ y del otro lado especialmente en el derecho de custodia y de visita.

Conseguientemente quiero presentarles el reglamento del derecho alemán con respecto a la custodia y la visita. Voy a exponer las reglas normativas actuales, los Constitucional causaron, la práctica de los tribunales de instancia y la reforma y sus causas como además, la comparación con cambios que las decisiones de la Corte

las exigencias de la Convención sobre los derechos del niño.

\section{Derecho de custodia sobre los hijos matrimoniales}

Durante la existencia del matrimonio, los padres están conjuntamente encargados de la custodia sobre los hijos comunes, $\S 1626 \mathrm{BGB}^{34}$. La cuestión de la repartición del derecho y de la obligación de la custodia, se plantea en el caso de la separación y especialmente del divorcio de los padres.

\section{a) Ley actual}

Antes la cuestión, quién de los dos cónyuges, tuvo la culpa por el fallo de matrimonio era decisivo también para el reparto del derecho de custodia ${ }^{35}$. Con la introdución de un nuevo derecho de divorcio en el año $1977^{36}$, que abandonó el concepto de la culpa, se cambiaron también las reglas para el reparto del derecho de custodia. Por la ley sobre la custodia del año $1979^{37}$, se cambió la denominación de patria potestad (elterliche Gewalt) en cuidado paternal (elterliche Sorge). El reparto de la custodia en caso de divorcio, fue sometido aun más a la consideración del interés del hijo ${ }^{38}$.

31. Nichtehelichengesetz del 19.8.1969, en vigor desde el 1.7.1970.

32. BverfG 23.10.1958, BverfGE 8, 210, 216; BVerfG 29.1.1969, BVerfGE 25, 167, 184.

33. El mencionado "Erbrechtsgleichstellungsgesetz" (ver N. Erro! Apenas o documento principal.) visa al la eliminación de estas diferencias.

34. Tales reglas se encuentran en casí todos los estados, ver Dopffel, p. 583.

35. Henrich (1995) p. 235; Beitzke/Lüderitz, p. 323.

36. Erstes Gesetz zur Reform des Ehe- und Familienrechts del 14.7.1976 (BGBI. I, 1421), in vigor desde el 1.7.1977.

37. Gesetz zur Neuregelung des Rechts der elterlichen Sorge del18.7.79 (BGBI. I, 1061), in vigor desde el 1.1.1980.

38. Henrich (1994) p. 185. 

cerse de oficio junto con el procedimiento los excónyuges. El otro podía obtener sola-
La ley actual prescribe que la atribución del derecho de custodia tiene que hadel divorcio. El reparto tiene que hacerse tomando en cuenta el interés del hijo, $\$$ 1671 BGB. El código civil fijó en $\S 1671$ par. 4, 1, expresamente que el derecho de custodia sólo puede ser atribuido a uno de mente un derecho de visita. Esta regla fue declarada inconstitucional y nula por la Corte Constitucional en el año $1982^{39}$. E art. 6 par. 2 de la Constitución constata que el cuidado y la educación de los hijos son primordialmente el derecho y la obligación de los padres. La comunidad estatal supervisa su ejercicio. La Corte Constituciona declaró que la garantía constitucional del cuidado y de la educación por los padres existe primeramente en el interés de la protección del hijo. Toda intervención estata tiene que ser justificada. La Corte Constitucional dictó que el estado no puede in tervenir cuando ambos padres, después de divorcio, son capaces y están dispuestos a ejercer el derecho y la obligación del cuida do en forma conjunta cuando no existe tampoco un interés del hijo a la atribución a un padre sólo.

En consecuencia de la decisión de la Corte Constitucional, el derecho de custodia puede ser ahora atribuido a los dos

excónyuges juntos. Por regla general, el tribunal ordena la custodia común, cuando los dos padres presentan una solicitud que quieren ejercer la custodia en común, cuando son capaces para la educación y cuando el tribunal considera que una custodia común está en el interés del hijo y es realizable a largo plazo ${ }^{40}$. En la práctica se pueden constatar diferencias regionales muy marcadas en cuanto al número de decisiones, que atribuyen la custodia común: En unas regiones la atribución de la custodia común alcanza hasta el $35 \%$, mientras en otras regiones solo hasta el $2 \%$ de los $\operatorname{casos}^{41}$.

\section{b) La nueva ley}

La nueva ley suprime la necesidad de una decisión sobre la custodia en caso de un divorcio. Sólo si uno de los padres presenta una solicitud, de ser encargado el solo con la custodia, el tribunal tiene que decidir sobre la atribución de ésta, $\$ 1671$ par 1 BGB (reformado). Sin solicitud, la custodia sigue estando a cargo de los dos padres. En la práctica, la necesidad de presentar una solicitud pondrá al padre, que quiere obtener la custodia en su favor, la carga de provar que el ejercicio común no funcionará. Esto vale más, tanto por el hecho que en la práctica la custodia común, no significa que todas las decisiones tienen que tomarse conjuntamente ${ }^{42}$.

\section{BVerfG 3.11.1982, BVerfGE 61, 358}

40. Gernhuber/Coester-Waltjen, p. 1037 s., N. 3; Beitzke/Lüderitz, p. 325.

41. Motivos del proyecto de ley, p. $36 \mathrm{~s}$.: En 1994/1995 en promedio general la custodia fue atribuida a ambos padres en común en $17 \%$ de los casos, a la madre en $74.6 \%$ de los casos y al padre en $8,3 \%$ de los casos; Reeken, Der Paradigmawechsel bei der elterlichen Sorge, DAV 1996, 672, 674.

42. Schwab/Wagenitz, 1380; hay dos modelos de ejercer la custodia en común: Modelo integrativo, el hijo vive con un padre y mantiene relaciones personales con el otro padre; modelo alternando, el hijo vive alternando con uno y con el otro padre; sólo en el último modelo los padres tienen que cooperar más estrechamente; una investigación llevado a cabo en Hamburgo mostró que solamente en $11 \%$ de los casos de custodia común se realizó el modelo alternando, Motivos del proyecto de ley, p. $36 \mathrm{~s}$

Revista da Faculdade de Direito da UFRGS, v. 13, 1997
La nueva ley prevee que el padre, con el cual el hijo está viviendo, puede decidir solo sobre todos asuntos de la vida cotidiana. Para estos asuntos no existe entonces la necesidad de ponerse de acuerdo con el otro padre. Sólo en asuntos de mayor importancia, como cuestiones de la educación escolar o de la residencia, existe la necesidad de tomar decisiones realmente en común, § 1687 BGB (reformado). El § 1687 par. 1, 3 BGB (reformado) específica que las deciciones de la vida cotidiana son por lo general todas las deciciones que se toman frecuentamente y que no tienen un impacto dificil de cambiar para la vida del menor. De hecho, el derecho de custodia del otro padre consiste en un derecho de visita reforzado por el derecho de codecisión en asuntos de mayor importancia.

Un reparto de la competencia sobre la educación y el cuidado de esta manera parece la más adecuada, según los conocimientos psicológicos y sociales de hoy día. En los años setenta la opinión predominaba que una educación sin conflictos era de importancia esencial para el desarollo sano del niño. El hijo debería ser protegido de las disputas entre los padres. Por ésto, fue concebido preferible, que la custodia del hijo sea atribuida de una vez sólo a uno de los padres, con el fin que permaneciera siempre con éste. Pero la atribución de la custodia a un solo padre resultó tener efectos desventajosos ya que, el otro padre se sintió excluido y frecuentemente se retiró. La relación personal entre hijo y padre se desvaneció en muchos casos. De esta manera, la separación de los padres significó para los hijos la perdida de la relación personal con un padre. Varias investigaciones demostraron que el hecho, de que muchos niños crecieron con la madre y no tuvieran relaciones estables con el padre, desfavoreció un desarollo sano de la personalidad del menor ${ }^{43}$.

De ahí surgió la tendencia de promover la custodia de ambos padres ${ }^{44}$. Aunque parece que la custodia común, en sí misma, no garantiza que los dos padres se encargen conjuntamente y con la voluntad de cooperación de la educación del menor ${ }^{45}$. La ventaja de la custodia común se estima hoy más en que puede iniciar un cambio de conciencia. Los hijos no tienen el sentimiento de perder un padre. Y el padre no se siente excluido de la responsabilidad con su propio hijo ${ }^{46}$. De esta manera, la posibilidad de la custodia común reduce también
43. Pero Nave-Herz, p. 103 critica que las investigaciones, que demostraron la tesis de deficit no tomaron en cuenta la multitud de diferentes causas que tienen efectos en el desarrollo de un niño, como por ejemplo la situación económica y social de la madre, que cria su hijo sola.

44. § 1626 par. 3, 1 BGB (reformado) consta: Zum Wohl des Kindes gehört in der Regel der Umgang mit beiden Elternteilen (EI bienestar del niño requiere generalmente que tenga contactos personales con ambos padres); en la mayoría de los estados europeos la custodia común después del divorcio es posible, bien que la practica difiere mucho en los diferentes estados, ver Dopffel, p. 589 ss. 45. Nave-Herz, p. 104: Para que el padre mantenga relaciones personales con su hijo la posición legal sólo es un factor; otros
factores importantes son la distancia geográfica, el lapso de tiempo transcurrido desde la separación, la edad del menor y la personalidad del padre.

46. En varios estados, por ejemplo Inglaterra, España, Italia y Francia, ambos padres mantienen en todo caso el derecho de custodia. Por decisión judicial solo se atribuye el derecho de ejercer este derecho de custodia, ver Dopffel, p. 586; tal regla tiene sobre todo un carácter simbólico, cuando el derecho de custodia no está ligado con el derecho de ejecerlo. En Inlgaterra es decisivo la decisión del tribunal sobre la residencia del hijo. El padre con el cual el hijo vive puede tomar casi todas las decisiones autónomo; el otro padre tiene que solicitar una decisión judicial para corregir decisiones o limitar al otro padre, ver Buettner, $469 \mathrm{~s}$.

Revista da Faculdade de Direito da UFRGS, v. 13, 1997 
el potencial de conflictos, en el momento del divorcio. Sobre la cuestión de la atribu ción de la custodia pesaba el miedo de perder el hijo. La necesidad de la atribución forzó a una decisión sobre la idonealidad de criar el hijo. Un padre siempre resultó el perdedor.

En Alemania la cuestión se discutió si es aconsejable que en todo caso de divorcio el tribunal decida sobre la custodia, atri buyéndola a un padre solo o dejándola a los $\operatorname{dos}^{47}$. En la ley vigente la custodia común ya no está excluida. Pero el tribunal tiene que decidir de oficio, conjuntamente con el divorcio sobre la custodia. La nueva ley favorece la solución, de que una decisón sólo se tome cuando un padre solicita la atribución de la custodia a él solo, § 1671 BGB (reformado) ${ }^{48}$.

Esto me parece de preferencia. El sólo hecho que la cuestión de la custodia sea objeto de un procidimiento judicial aumenta más bien los conflictos y disminuye la posibilidad de mantener la custodia común ${ }^{49}$. Sin procedimiento obligatorio, los padres pueden encontrar una solución fexible. La continuación de la custodia común no está bajo la obligación de ser justi- ficada. La solicitud de la atribución exclusiva tendría que justificarse ${ }^{50}$. Hay que ver también, que aún en el caso de custodia común no existe la necesidad de que ambos padres discutan y decidan cada asunto. Como ya he mencionado, la nueva ley quiere introducir la regla que el padre con el cual el hijo vive tiene también el derecho de decidir sobre todos los asuntos de la vida cotidiana $^{51}$. De esta manera una custodia común parece realizable, a pesar que existen conflictos en la relación entre los padres. Es verdad que en muchos casos los padres no pueden diferenciar entre los sentimientos personales hacia el excónyuge y sus papeles y obligaciones como padres de un hijo común. Pero si la custodia común no exige la constante coordinación, se puede también realizar cuando no existe la facultad y la dispocisón optimal para la cooperación ${ }^{52}$.

Recientemente unos tribunales de primer instancia han comenzado a mantener la custodia común, a pesar de que el padre con el cual el hijo vive diariamente se oponía. La atribución de la custodia a un padre solo, es una intervención en el derecho del otro padre y tiene que ser exigida
47. Motivos del proyecto de ley, p. 60 s.; Gernhuber/Coester-Waltien, p. 1033; Henrich (1994) p. 193 s.; Coester (1996) p. 1185; en la mayoría de los estados europeos una decisión judicial sobre la custodia es obligatoria en caso de divorcio; la ley induce en
muchos estados a los padres a encontrar un acuerdo que sirve como base esencial para la decisión judicial; el divorcio más facil y rápido solo se puede dictar, cuando tal acuerdo sobre la custodia existe, ver Dopffel, p. $584 \mathrm{~s}$.

48. Motivos del proyecto de ley, p. 61.

49. Baer (1989) p. $347 \mathrm{~s}$

50. Coester (1996) p. 1185 propone que solo un acuerdo explícito de los padres permite desistir a una decisión judicial; además, subraya la necesidad de aumentar las posibilidades de acompañar y aconsejar a los padres por expertos de trabajo social; subraya la necesidad de aumentar las posibilidades de acompañar y aconsejar a los padres por expertos
Henrich (1994) p. 194 favorece una decisión judicial obligatoria acompañada por asesoramiento psicológico.

51. Otro reparto del derecho de custodia entre los padres es también posible; para que tal reparto tenga una base legal, la reforma exige una decisón judicial, § 1671 BGB (reformado); ver la crítica en la necesidad de una decisión judicial para tal acuerdo Coester (1996) p. 1186.

52. Motivos del proyecto de ley, p. $62 \mathrm{~s}$.

Revista da Faculdade de Direito da UFRGS, v. 13, 1997 por el interés del hijo. Por el interés del hijo, los padre tenien la obligación a ponerse de acuerdo, si necesario con la ayuda de expertos sociales ${ }^{53}$. La nueva ley introduce la ayuda social regular para que los padres acepten y pueden realizar mejor la custodia común.

\section{c) Conclusión}

Se puede comprobar que la custodia común corresponde más al interés superior del niño. Para el bienestar del niño es de gran importancia que después de la separación ambos padres sigan encargandose de él. Así se evita que el hijo sienta la perdida de un padre. La ocupación de ambos padres es favorecida por la custodia común, que mantiene el derecho y la obligación de velar por el hijo. Sólo cuando el bienestar del hijo se vea amenazado porque los padres nollegan a arreglar el asunto de la custodia, sin mezclarlo con sus disputas personales, la atribución de la custodia a un solo padre parece necesario para el interés superior del niño. Mientras que según la ley actual, la custodia común despues del divorcio es todavía la excepción, la nueva ley visa a hacer la custodia común como lo normal. Suprima la necesidad de tomar una decisión judicial sobre la custodia en el proceso de divorcio y instala una ayuda social regular para promover que los padres puedan aceptar y realizar la custodia común. De esta manera la nueva ley está confomre con el art. 18 par. 1 de la Convención.

\section{Derecho de custodia sobre los hijos extramatrimoniales}

Después de haber presentado el reglamento de la custodia sobre los hijos matrimoniales, quiero ahora tratar el caso de los hijos nacidos fuera de un matrimonio.

a) Ley actual

La ley actual atribuye la custodia sobre los hijos extramatrimoniales exclusivamente a la madre, $\S 1705$ BGB. El derecho de custodia de la madre está limitado por la tutela oficial. Ésta entra en vigor automaticamente con el nacimiento del niño. Esta tutela contiene la representación del menor en ciertos asuntos. Se trata especialmente de las relaciones del niño con su padre y la familia paternal como la declaración o investigación de la paternidad, la acción de hacer valer los derechos alimenticios o los derechos sucesorios, $\$ 1706$ BGB. Vale remarcar, que la tutela oficial no fue introducida en el territorio de la antigua República Demócrata Alemana. Así la custodia de la madre sobre un niño extramatrimonial nacido en el territorio de la antigua RDA, no está restringido por la tutela oficial ${ }^{54}$.

La ley actual no contiene la posibilidad que los padres no casados puedan obtener la custodia común sobre un hijo. La custodia puede ser atribuída bajo ciertas condiciones al padre, pero ésto trae siempre la consecuencia, de que la madre pier-

53. Decisiones de AG GroB-Gêrau 26.8.1993, FamRZ 1993, p. 992 y AG Mannheim, 16.9.1993, citado por Rummel, Die Rechtsprechung zum Sorgerecht aus den Jahren 1993/94, FuR 1995, p. 129, 130 s.; OLG Bamberg 14.3.1995, FamRZ 1995, Rechtsprechung zum Sorgerecht
$1168 ;$ muy critico Giesen, N. 675.

54. Art. 230 par. 1 EGBGB; Beitzke/Lüderitz, p. 332 s.; Giesen, N. 691. 
de el derecho de custodia. Una posibilidad consiste en la declaración de la legitimidad del hijo por parte del padre, $\S \S 1723$ ss. BGB. Por consecuencia, el hijo vuelve a ser hijo legítimo del padre, $\S 1736$ BGB. El padre obtiene el derecho de custodia, pero la madre lo pierde obligatoriamente, § 1738 BGB.

La Corte Constitucional declaró como inconstitucional que los padres, que tienen un hijo y que están cuidandolo juntos no pueden lograr obtener el derecho de custodia en común, cuando no están casa$\mathrm{dos}^{55}$. Como la inconstitucionalidad no podía ser eliminada por la declaración de nulidad de una regla normativa y como el legislador posee un margen de discrecionalidad, la Corte Constitucional reclamó una reforma de ley.

La regla del derecho alemán, que atribuye la custodia sobre un hijo extramatrimonial necesariamente a la madre y permite la custodia del padre solo cuando la madre pierda la custodia, es también contraria al art. 18 de la convención ${ }^{56}$ al igual que al art. 8 de la Convención de los los derechos humanos del Consejo de Europa ${ }^{57}$.

55. BVerfG 7.5.1991, BVerfGE 84, 168, la decisión se limita a la mencionada regla que una válida declaración de legitimidad por parte del padre entrena necesariamente la perdida de la custodia de la madre.

\section{Meng, p. 24}

57. Broetel (1996) p. 62; AG München 23.8.1996, FamRZ 1997, 237 que supone una oposición contra Art. 6 par. 2,1 y par. 4 de la Constitución y se refiere expresamente a la Convención de los los derechos humanos del Consejo de Europa y a la Convencion sobre los derechos del niño.

58. Motivos del proyecto de ley, p. 37; Statistisches Jahrbuch 1996 fuer die Bundesrepublik Deutschland, p. 70; última estadistica del ano 1994; estas y más informaciones estadísticas sobre Alemania se pueden encontrar en el Internet (http://www.statistik-bund.de)

59. Estadisticas para el año 1994: 189000 en el terriorio de la antigua RDAy 220000 en el territorio de la antigua RFA. Se estima que en estas uniones de hecho viven 272000 respectivamente 313000 menores (no necesariamente hijos comunes), Motivos del proyecto de ley, p. 38 .

60. Henrich (1995) p. 245. custodia conjuntamente. No se considera como necesario originar en estos casos una decisión judicial que juzgaría sobre la conformidad del acuerdo de los padres con el interés del hijo. Padres, que no están casados y que declaran la voluntad de educar y cuidar un hijo en común, parecen idóneos para esta taréa en el mismo grado como dentro un matrimonio. No hay razón para desconfiar en ellos ${ }^{61}$. Los padres no tienen que probar que están viviendo juntos o que no están casados con otra persona. La custodia en común está también a la disposición de padres que desde el principio no viven en común. Cuando los padres se separan, se aplica la misma regla como en el caso de divorcio. La custodia común qùeda vigente. Solamente cuando un padre lo solicita, el tribunal decidirá, a cuál padre atribuirá la custodia.

Si los padres no se pueden poner de acuerdo de ejercer la custodia conjuntamente, la nueva ley siempre atribuye el derecho de custodia exclusivamente a la madre $^{62}$. No introduce la custodia común como regla general también para hijos extramatrimoniales. De esta manera, la custodia común no entra en vigor si los padres no la han expresamente solicitado.

En favor de esta solución se puede invocar, que los padres de hijos matrimoniales no viven siempre en una unión de hecho estable. En muchos casos no existen

61. Coester (1996) p. 1184.

62. La tutela oficial que entra en vigor automaticamente será remplazada por una asistencia a voluntad por la Beistandschaftsgesetz. ver N. Erro! Apenas o documento principal.

63. Dopffel, p. 600.

64. Coester (1995) p. 1247

65. Ver la crítica de esta regla por Coester (1995) p. $1247 \mathrm{~s}$. relaciones personales fundadas y estables entre los padres y entre el padre y el hijo. En estos casos, una regla general de la cus. todia común causaría problemas ${ }^{63}$. Muchas veces no se puede localizar al padre. Los padres, que talvez nunca han vivido juntos y no se conocen muy bien, tendrían que ponerse de acuerdo. Además, el padre puede ser dificil de localizar cuando una decisión tiene que ser tomada. La nueva ley considera como base necesaria para la custodia común, que ambos padres están dispuestos a ejercer la custodia de esta forma ${ }^{64}$. Si los padres no viven en común, existe por lo general una precedencia de la madre. El hijo recién nacido no puede prescindir de la madre.

La nueva ley rechaza también la posibilidad de que el padre pueda solicitar que el tribunal le atribuya el derecho de custodia con el argumento de que él sea lo más idóneo. Tal reglamento pondrá al padre en una posición más equivalente a la posición del padre de un hijo matrimonial después del divorcio ${ }^{65}$. Por otro lado, tal pỏsibilidad pondría una cierta presión sobre la madre con la consecuencia posible, que por mie. do de perder el hijo, intente de impedir todo contacto entre hijo y padre. La nueva ley sale de la consideración de que la discriminación del padre está equilibrada, en parte, por un derecho de visita y que se justifica por el interés de una estable relación del 
niño con la madre. La consecuencia de la posición dominante que la nueva ley atribuye a la madre es, que ella puede decidir de excluir al padre de la custodia.

Tomando como criterio principal el interés superior del menor no me parece necesario que la madre pueda excluir al padre de la custodia. Bien que uno puede argumentar que el caso es distinto, cuando una pareja criando juntos un hijo, se separa. En esta situación el hijo tenía, por lo general, relaciones afectivas con ambos padres y el interés del hijo está orientado a la continuación de estas.

La importancia de buenas relacione personales con ambos padres existe también el caso que los padres nunca han vivido juntos. Los intereses del padre tienen que ser también tomados en consideración. Esto es óbvio cuando el hijo fue engendrado durante una unión de hecho y los padres se separaron antes del nacimiento. En el caso de un matrimonio la separación o el divorcio antes del nacimiento no cambia la regla general de que ambos padres tienen la cus todia común. En el ámbito del reparto de derecho de custodia después de un divorcio la atribución sólo de un derecho de vi sita al padre que perdió la custodia, resultó por lo general no ser suficiente para asegurar y promover relaciones personales eficaces entre padre e hijo.

Por esta razón me parece preferible que el padre de un hijo extramatrimonial

66. Ver Broetel (1996) p. 64, que considera un derecho de veto de la madre contra la custodia común con el padre del hijo extramatrimonial contrario al art. 8 Convención de los los derechos humanos del Consejo de Europa; ver también el infomre
sobre el debate en el Rechtsausschuß des Deutschen Bundestag (la comisión parlamentaria juríica), Bundestag Drucksache sobre el debate en

67. Merkt, en Dopffel, p. 473,480 pueda obtener la custodia a la par de la custodia de la madre sin excluir a ésta ${ }^{66}$. Por esto no sería necesario de que la custodia común entraría en vigor automaticamente con el nacimineto del niño. Pero el padre interesado en el hijo tiene que tener la posibilidad de encargarse de la vida de éste en una forma más intensiva que permita un solo derecho de visita. Una solución podría ser que el padre tendrá el derecho de pedir que el tribunal le atribuye la custodia a la par de la madre.

Tal posibildad existe en unos estados en los Estados Unidos ${ }^{67}$. Bien que la custodia común exige como base la disposición de cooperar, la custodia común, en la forma como está prevista por la nueva ley, no implica la necesidad de ponerse de acuerdo en todos los asuntos. La custodia de consiste en un derecho de visita y en el derecho de ser consultado en decisiones de mayor importancia. De esta manera la posibilidad que el tribunal ordene la custodia común, obligaría más a la madre de aceptar el papel del padre.

Pero parece que la ley alemana todavía no está lista para aceptar una solución que atribuya la custodia conjuntamente, a en compartirla. Es posible que se necesite primero un tiempo de experiencia, que la custodia común funcione también si la relación de los padres no está harmoniosa. padre, con el cual el hijo no está viviendo, pesar de que la madre no está de acuerdo
Esto me parece posible por la regla que la custodia común no significa que todas las decisiones tienen que ser tomadas conjun tamente. Por el momento, tal regla no es realizable para los hijos extramatrimoniales en el ámbito político en Alemania.

Puede ser que estamos en el camino, que más tarde llegue, a que dicha regla se aceptada. Hay que ver que el punto de salida era la obligación de atribuir la custodia a uno de los dos padres exclusivamente después de un divorcio. Padres que no están casados no tienen hasta ahora la posibildad de obtener la custodia común para sus hijos. El próximo paso fue tomado por la Corte Constitucional, en que la custodia puede ser atribuida por el tribunal a los dos padres cuando ambos lo solicitan. La reforma da un paso en el sentido que la custodia debería ser la regla cuando los padres que la ejercían conjuntamente se separan. La atribución a un solo padre solo se puede ordenar, si el otro padre consiente o si se justifica por el bien del menor, $§ 1371$ BGB (reformado). El próximo paso, de que los padres están en el interés del niño obligados de aceptar la custodia del otro padre, parece todavía no realizable. Un movimiento en esta dirección sería, si la continuación de la custodia común después de la separación o del divorcio, como está prevista en la nueva ley, se desarollará como el estandard. Es decir, si la oposición de un padre, especialmente de la madre en caso de niños de poca edad, de compartir la custodia con el otro padre, no justificará la atri-

bución de la custodia a ella exclusivamente. Cuando tal reglamento da buenos resultados en este ámbito, una extensión a los padres de hijos extramatrimoniales puede ser pensada y será más realizable. Hay que ver que la nueva ley es relativamente progresiva para las condiciones alemanas ${ }^{68}$.

A pesar de ésto, no la nueva ley no me parece contrario al art. 18 par. 1 de la Convención sobre los derechos del niño. Hay que tomar en cuenta que las experiencias todavía no existen como funcionará la nueva forma de custodia común. Pero si la custodía comun da buenos resultados una posición más fuerte del padre de un hijo extramatrimonial me parece todavía más conforme con el espíritu del art. 18 par. ${ }^{69}$.

\section{Derecho de visita}

Después de haber tratado el derecho de custodia quiero abordar el derecho de visita que se atribuye por lo general al padre que no goza del derecho de custodia.

\section{a) Ley actual}

La ley actual hace una diferencia en cuanto al derecho de visita entre los hijos matrimoniales y extramatrimoniales. En cuanto a los hijos matrimoniales, el código civil actual confirma que el padre, que no tiene el derecho de custodia, siempre tiene el derecho de visita ( $\$ 1634$ I 1 BGB). En caso de diferencias, en cuanto al ejercicio de este derecho de visita entre los dos padres, el tribunal de familia está encargado de dictar las reglas apropiadas.

68. Critico por este motivo Schwab/Wagenitz, p. 1383.

69. Además, el texto literal del art. 18 es vago y impreciso y así no proporciona criterios exactos para decidir sobre la compatibilidad 0 imcompatibilidad de reglas nacionales, ver Meng, p. 28. 
En cuanto a los contactos entre el hijo extramatrimonial y el padre, la ley actual concede a la persona encargada del derecho de custodia, es decir normalmente a la madre, el derecho de decidir sobre estos contactos. Si la madre no conciente, el padre puede solicitar una decisión del tribunal tutelar. Este puede atribuir un derecho de visita al padre cuando sirve al bienestar del hijo ( $\$ 1711$ BGB). Antes un derecho de visita fue concedido contra la voluntad de la madre solamente en casos de una antigua unión de hecho de los padres. Hoy en día, unos tribunales están más abiertos a reconocer el propio interés del hijo de tener relaciones personales con el padre. Existen grandes diferencias según el tribunal encargado. En la práctica los tribunales se abstienen muchas veces de conceder un derecho de visita cuando la madre se opone ${ }^{70}$. La relación entre padre e hijo extramatrimonial está caracterizada por derechos relativamente fuertes en cuanto a lo alimenticio y a la sucesión. Pero las relaciones personales casi no son apoyadas por la ley ${ }^{71}$.

\section{b) La nueva ley}

La nueva ley introduce el derecho de visita de cada padre sin diferenciar entre hijos matrimoniales y extramatrimoniales.

En el proyecto de ley, elaborado por el gobierno, la regla propuesta utilizó solo

la noción del derecho del padre de mantener contactos con su hijo. Bien que los motivos del proyecto ponían el énfasis en el interés del hijo en los contactos con el padre con el cual no vive, el texto literal de la propuesta regla no previó una obligación del padre. El proyecto desaprobó la introducción de un derecho del hijo a pedir contactos en relación con el padre no encargado de la custodia ${ }^{72}$. En el proceso legislativo se cambió el proyecto del gobierno y fue introducido en $\$ 1684$ p. 1 BGB (reformado) que el niño tiene un derecho de visita y que cada padre tiene la obligación y el derecho de visita ${ }^{73}$.

El proyecto rechazó todavía tal proposición con el argumento que tal reglamento causaría gran derroche sin mejorar la situación efectivamente. Establecer no solo un derecho pero al igual una obligación de visita corresponde también a las exigencias de la Convención sobre los derechos del niño, al igual a las de la constitución alemana. Según ambas fuentes, el derecho de los padres hacia sus hijos consiste al mismo tiempo en una obligación de cumplir el papel de padre ${ }^{74}$. A un lado es obvio, que contactos forzados contra la voluntad del padre solo pueden ser formales y no estén en el interés del hijo ${ }^{75}$. La inclusión de una obligación del padre de tener contactos con el hijo es por ésto primordialmente simbólica. La nueva regla se entiende sobre todo como

\section{Gernhuber/Coester-Waltjen, p. 932}

71. Beitzke/Lüderitz, p. 334 ss.; Dopffel, p. 605 , que caracteriza el derecho alemán como muy conservador en comparación con los derechos de los otros estados europeos.

72. Motivos del proyecto de ley, p. 68 .

73. Rechtsausschuß des Deutschen Bundestag (la comisión parlamentaria juridica), Bundestag Drucksache 13/8511, II.B.2.a).

74. Gernhuber/Coester-Waltjen, p. 1063.

75. Giesen, N. 685; Henrich (1994) p.198 s., que critica que tribunales en los Estados Unidos han acordado al hijo un derecho de indemnización por los costos del cuidado por otra persona.

Revista da Faculdade de Direito da UFRGS, v. 13, 1997 señal para cambiar la consiencia de los padres $^{76}$. El derecho del niño establece también una obligación del padre que tiene el derecho de custodia de permitir el contacto con el otro padre. Así la ley hace más claro que la cuestión de la visita no es solo un asunto de disputa entre los dos padres, pero que toca el interés y el derecho propio del hijo ${ }^{77}$.

También la Convención sobre los derechos del niño percibe los contactos de niño con sus padres como un derecho de mismo hijo. Y éste existe también contra e padre encargado de la custodia de respetar los contactos con el otro padre ${ }^{78}$.

\section{Conclusiones}

Sacando conclusiones llegamos a notar, que la Convención de las Naciones Unidas sobre el derecho del niño estipula un ordenamiento de valores fundamenta les en la materia. A pesar de que en la mayoría no estipula obligaciones que pueden ser invocadas directamente por los ciudadanos, pero se limita a imponer a los estados obligaciones de una manera que deja a estos un margen de discreción al cumplirlas. Toma mucha importancia por ser el punto de referencia de la discusión sobre posibles reformas de la ley interna. Este efecto se refuerza por el trabajo del comité de supervisión al cual cada estado tiene que

rendir un informe sobre el cumplimiento de las obligaciones de la convención. Este informe tiene que ser también publicado en el mismo país. Esto facilita que la opinión pública ejerza una cierta presión para que las obligaciones se cumplan.

El derecho alemán de la custodia y la visita no cumple actualmente las exigencias de la convención. El derecho alemán no permite hasta el momento la custodia en común de los padres que no están casados $^{79}$. Además, el derecho de visita del padre de un hijo extramatrimonial que no está a cargo de la custodia está formulado de una manera muy debil.

La reforma realiza las exigencias de la convención en la materia de custodia y visita. Se introduce la custodia común después del divorcio de un matrimonio o de la separación du una unión de hecho de los padres como regla general. Así promovería la realisación del objetivo del art. 18 par. 1 de la convención que los dos padres se encargen de la crianza de su hijo aunque no vivan juntos. La nueva ley estipula claramente que la custodia y la visita son no sólo un derecho de los padres, pero también una obligación. Así la nueva ley correspande al espíritu de art. 18 y de la convención. La nueva ley significa un gran adelanto para la situación de los niños en Alemania.

76. Rechtsausschuß des Deutschen Bundestag (la comisión parlamentaria jurídica), Bundestag Drucksache 13/8511, II.B.2.a). 77. Rechtsausschuß des Deutschen Bundestag (la comisión parlamentaria jurídica), Bundestag Drucksache 13/8511, II.B.2.c). 78. Broetel (1996a) p. 849

79. Meng, p. 24. 